\title{
The Type of Conservative Management Could Be Related to the Strength of the Inspiratory Muscles of Adolescents with Idiopathic Scoliosis-A Case Series
}

\author{
Felipe León-Morillas ${ }^{1} \mathbb{D}$, Silvana Loana de Oliveira-Sousa ${ }^{2}\left(\mathbb{D}\right.$, Juan Alfonso Andrade-Ortega ${ }^{3}(\mathbb{D}$, \\ Alfonso Javier Ibáñez-Vera ${ }^{4, *(\mathbb{D})}$, Rafael Lomas-Vega ${ }^{4}$ iD and Noelia Zagalaz-Anula ${ }^{4}$ \\ 1 Department of Physiotherapy, Catholic University of Murcia UCAM, Avenida de los Jerónimos, \\ 30107 Murcia, Spain; fleon@ucam.edu \\ 2 Department of Physiotherapy, University of Murcia, 30100 Murcia, Spain; soliveira@um.es \\ 3 Department of Physical Medicine and Rehabilitation, Complejo Hospitalario de Jaen, Avenue of Madrid, \\ 23001 Jaén, Spain; juanalfonsoandrade@gmail.com \\ 4 Department of Health Sciences, University of Jaen, Campus de las Lagunillas, 23071 Jaén, Spain; \\ rlomas@ujaen.es (R.L.-V.); nzagalaz@ujaen.es (N.Z.-A.) \\ * Correspondence: ajibanez@ujaen.es; Tel.: +34-953-213-519
}

Citation: León-Morillas, F.; de Oliveira-Sousa, S.L.;

Andrade-Ortega, J.A.; Ibáñez-Vera, A.J.; Lomas-Vega, R.; Zagalaz-Anula, N. The Type of Conservative Management Could Be Related to the Strength of the Inspiratory Muscles of Adolescents with Idiopathic Scoliosis-A Case Series. Children 2021, 8, 1002. https://doi.org/

$10.3390 /$ children 8111002

Academic Editor: Angelo Gabriele Aulisa

Received: 21 October 2021

Accepted: 1 November 2021

Published: 3 November 2021

Publisher's Note: MDPI stays neutral with regard to jurisdictional claims in published maps and institutional affiliations.

Copyright: (c) 2021 by the authors. Licensee MDPI, Basel, Switzerland. This article is an open access article distributed under the terms and conditions of the Creative Commons Attribution (CC BY) license (https:/ / creativecommons.org/licenses/by/ $4.0 /)$.

\begin{abstract}
Adolescent idiopathic scoliosis (AIS) is a lateral curvature of the spine with a Cobb angle of at least $10^{\circ}$ with an unknown etiology. It is recognized that AIS may affect respiratory function. This study aims to describe and compare respiratory function in a case series of patients with scoliosis who underwent different types of therapeutic management: no intervention, orthotic brace, and global postural reeducation (GPR). Fifteen AIS patients were included in this study (seven no intervention, four orthotic brace and four GPR). Lung function and inspiratory muscle strength were measured and analyzed, as well as sociodemographic, clinical, and anthropometric variables. Significant correlations were observed between height $(\mathrm{cm})$ and maximum inspiratory pressure (MIP) reference $\left(\mathrm{cmH}_{2} \mathrm{O}\right)$ and forced vital capacity (FVC) (liters) $(r=0.650$ and $r=0.673$, respectively; $p<0.01$ ); weight $(\mathrm{Kg})$ and MIP reference $\left(\mathrm{cmH}_{2} \mathrm{O}\right)(r=0.727 ; p<0.01)$; and Main curve degrees (Cobb angle) and FVC $\%(r=-0.648 ; p<0.01)$. The AIS cases that underwent GPR treatment presented a greater MIP (\% predictive) compared to the no intervention and brace cases $(201.1 \%$ versus $126.1 \%$ and $78.4 \%$, respectively; $p<0.05$ ). The results of this case series show a possible relation whereby patients undergoing treatment with the GPR method have greater inspiratory muscle strength compared to the no intervention and brace cases. Studies with larger samples and prospective designs must be performed to corroborate these results.
\end{abstract}

Keywords: idiopathic scoliosis; respiratory muscle strength; lung function; global posture reeducation

\section{Introduction}

The process of ossification and volumetric growth of the spine is long-lasting, beginning in the third month of intrauterine life and lasting until the second decade of life. More than 130 growth plates working in perfect synchronization are involved in spinal growth. Idiopathic scoliosis (IS) is an evolutive growth plate disorder that produces negative effects on the growing spine [1]. Puberty is a turning point in children with IS as the pubertal growth spurt increases the risk of deformity progression [1]. Adolescent idiopathic scoliosis (AIS) is the most common form of scoliosis in children between 10 and 18 years of age (80-85\% of recorded cases). AIS is characterized by an unknown etiology and a lateral deviation by a Cobb angle of at least $10^{\circ}[2,3]$.

It is recognized that AIS may affect respiratory function. AIS reduces diaphragmatic movement and generates an uneven distribution of inhaled air, which is why it can affect lung function in these patients $[3,4]$. Several authors have shown a direct correlation between lung disability and the magnitude of the degree of deviation of the spine $[5,6]$. At 
Cobb angles greater than $60^{\circ}$, patients present severe functional restrictions in breathing [7]. Those with curvatures between $20^{\circ}$ and $45^{\circ}$ may find their maximum ventilatory capacity to be limited, manifesting in difficulties carrying out intense physical exercise [8]. Redding et al. also mentioned the relationship between forced vital capacity and Cobb angle in patients with AIS [9]. For this reason, correction and respiratory treatment in these patients are essential.

The management of scoliosis mainly depends on age (remaining growth), pattern of curve, severity of the deformity, risk of progression, and presence of comorbidities. Specifically, the remaining growth is especially important in the worsening of the curvature of the spine, since the risk of progression of the curve is greater in younger children. Furthermore, the pubertal growth spurt increases the risk of deformity progression with a significant number of cases substantially worsening [10]. Almost $10 \%$ of patients require some type of treatment and $0.1 \%$ end up undergoing surgery [8]. The scientific literature is in agreement that with appropriate indications-still-growing and well-documented progressive curves between $20^{\circ}$ and $45^{\circ}$ - a well-designed and adapted brace can provide a correction of $50 \%$, which can stop the curve's progression in most cases [8]. However, the effects of bracing on thorax mechanics, chest mobility, and pulmonary functions are considered inevitable [11]. Other conservative methods, based on exercise approaches, such as Schroth exercises [12], or Global Postural Reeducation (GPR) [13], may be beneficial and appear to cause fewer adverse effects because they allow the patient to move without restriction. Specifically, the GPR uses active muscle stretching postures, motor control and sensory integration exercises. The reduction in the scoliotic curve after GPR treatment has been measured during GPR active and assisted self-correction [13].

Some studies based on exercise approaches have shown reductions in Cobb angle and improvement in chest expansibility, vital capacity and respiratory muscle strength [12,14-17]. However, although these are promising therapies for the management of scoliosis, the available evidence is insufficient [12], especially with respect to the effects on respiratory function. Therefore, the objective of this study is to describe and compare lung function and inspiratory muscle strength in patients with AIS, under three different approaches to therapeutic management: no intervention, orthotic brace and GPR.

\section{Materials and Methods}

\subsection{Participants}

The design of this study was a retrospective case series. Patients with AIS aged between 10 and 18 years were treated between 10 September 2018 and 13 May 2019 at the Tertiary Hospital of Jaén (Andalusia, Spain) or at specialized private clinics or health centers (any with both rehabilitation doctors and physiotherapist in their staff) in the province we selected. Inclusion criteria were a Cobb angle greater than $10^{\circ}$ (which was assessed attending King Classification of AIS) and undergoing conservative treatment or no intervention. Patients with neuromuscular problems and surgical treatment were excluded. The study was designed and conducted in accordance with the World Medical Association Code of Ethics for studies with human participants (Declaration of Helsinki). The research protocol was approved by the Hospital de Jaén Ethics Committee (Code 0594-N-19, date of approval 30 May 2019). All of the participants were informed and voluntarily decided to participate in the study together with the agreement and consent of their legal guardians.

\subsection{Therapeutic Management}

On the one hand, patients with moderate curvature (20-45 degrees) were treated $8.25 \pm 2.86$ months (mean \pm standard deviation) with a Cheneau Brace, a type of orthosis effective in the treatment of scoliosis [18]. On the other hand, patients who presented with slight curvature (10-19 degrees) performed GPR exercises twice a month for $6.25 \pm 2.95$ months. This management consisted of maintaining the anteroposterior curves (the physiological kyphosis and lordosis) and correcting the lateral curves of the spine through a self-stretching and a "paradoxical" breathing (active descent of the diaphragm 
and abdominal and oblique contraction at the end of expiration) that increase the stretching at the affected side. These exercises could be performed with legs hung to increase the tension in the triceps surae, hamstring muscles and gluteus maximus (Figure 1) or with legs in closed chain to increase the tension of the psoas muscles (Figure 2), depending on a previous evaluation. The postures always evolve towards a tension increment by reducing hip angle or increasing hip angle, respectively, avoiding any compensation al lumbar spine. The GPR exercise reduces the asymmetry through muscle eccentric stretching guided by breathing and sensory inputs directed by the therapist [13].

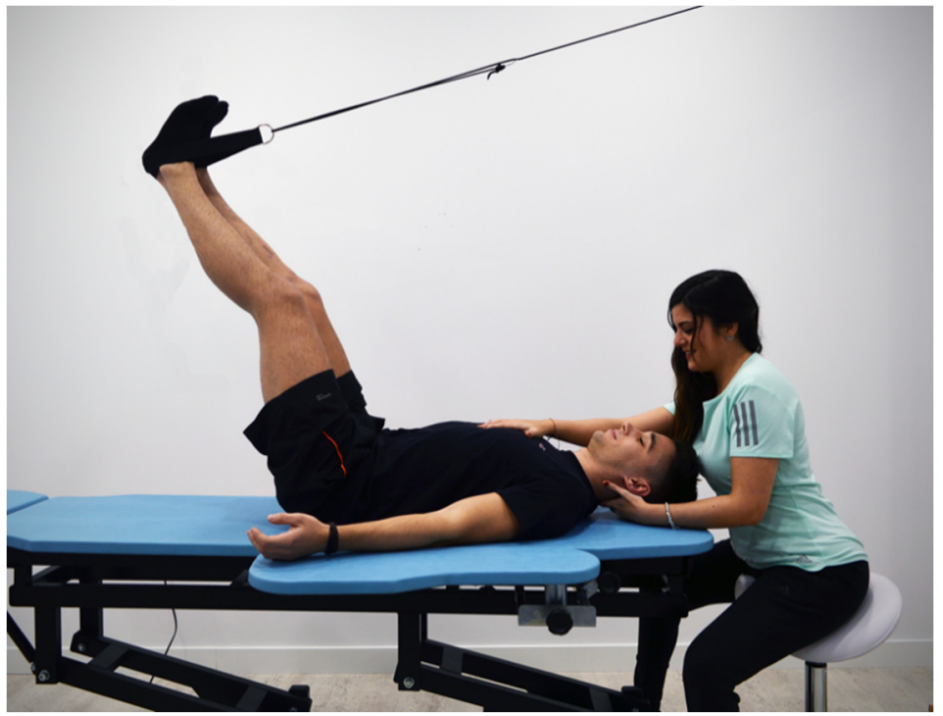

Figure 1. Example of GPR therapeutic management, with patient placed in lying position with lower limbs hanged to increase the tension in the triceps surae, hamstring muscles and gluteus maximus while asked to perform paradoxical breathing and spine corrections. The posture will evolve to increase in hip flexion.

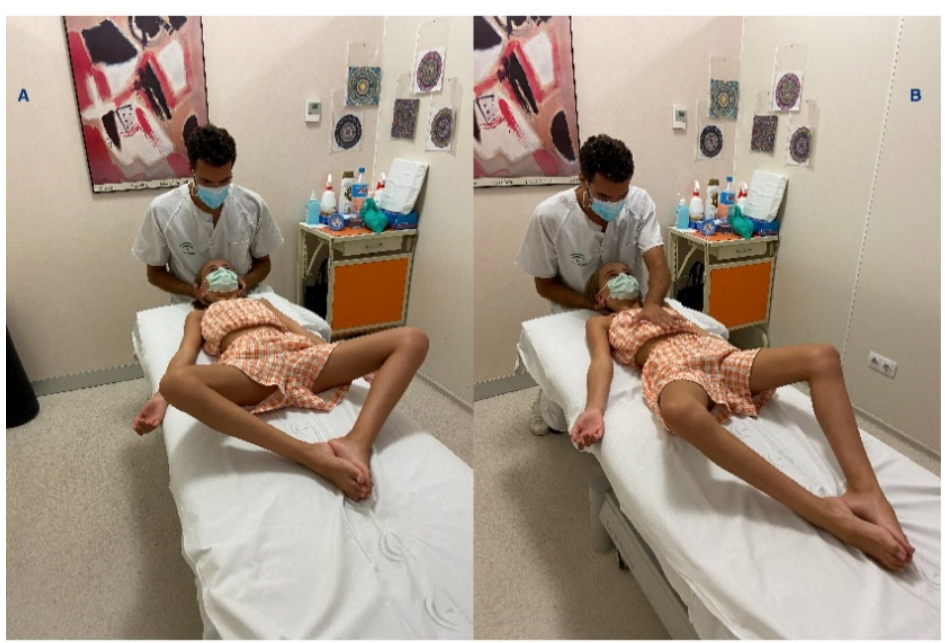

Figure 2. Example of GPR therapeutic management, with patient placed in lying position with lower limbs in closed chain position to increase the tension of the psoas muscles while asked to perform paradoxical breathing and spine corrections (A). The posture will evolve to reduction in hip flexion (B).

\subsection{Measurements}

The diagnosis of AIS was made by a physician specializing in Physical Medicine and Rehabilitation. Cobb angle was measured to be greater than or equal to $10^{\circ}$ through anteroposterior X-ray. There are five types of scoliotic curve, according to the King Classification [19] of AIS: "S-shaped curve" in which both the thoracic curve and the lumbar curve 
cross midline and lumbar curve larger than thoracic curve on standing roentgenogram (Type I); "S-shaped curve" in which the thoracic curve and the lumbar curve cross the midline. Thoracic curve $\geq$ lumbar curve (Type II); the thoracic curve in which the lumbar curve does not cross the midline (Type III); long thoracic curve in which the fifth lumbar vertebra is centered over the sacrum but the fourth lumbar vertebra tilts into the thoracic curve (Type IV); the double thoracic curve with the first thoracic vertebra tilted into the convexity of the upper curve. The upper curve structural on side-bending (Type V). Sociodemographic, clinical, and anthropometric variables were collected and written down by the same researcher in all of the patients at the same time point, regardless of the time of evolution of the treatments.

Inspiratory muscle strength measurements were performed indirectly on the basis of maximum inspiratory pressure (MIP). A peak inspiratory mouth pressure monitor was used. With respect to lung function (respiratory volumes), forced vital capacity (FVC) and forced expiratory volume in the first second $\left(\mathrm{FEV}_{1}\right)$ were measured using a digital inspirometer (Datospir Thouch, Sibelmed, Barcelona, Spain). These measurements were recorded by a previously trained physiotherapist (Figure 3). Three measurements of each variable were taken, and the best result was recorded, in line with the protocol established by the American Thoracic Society [20].

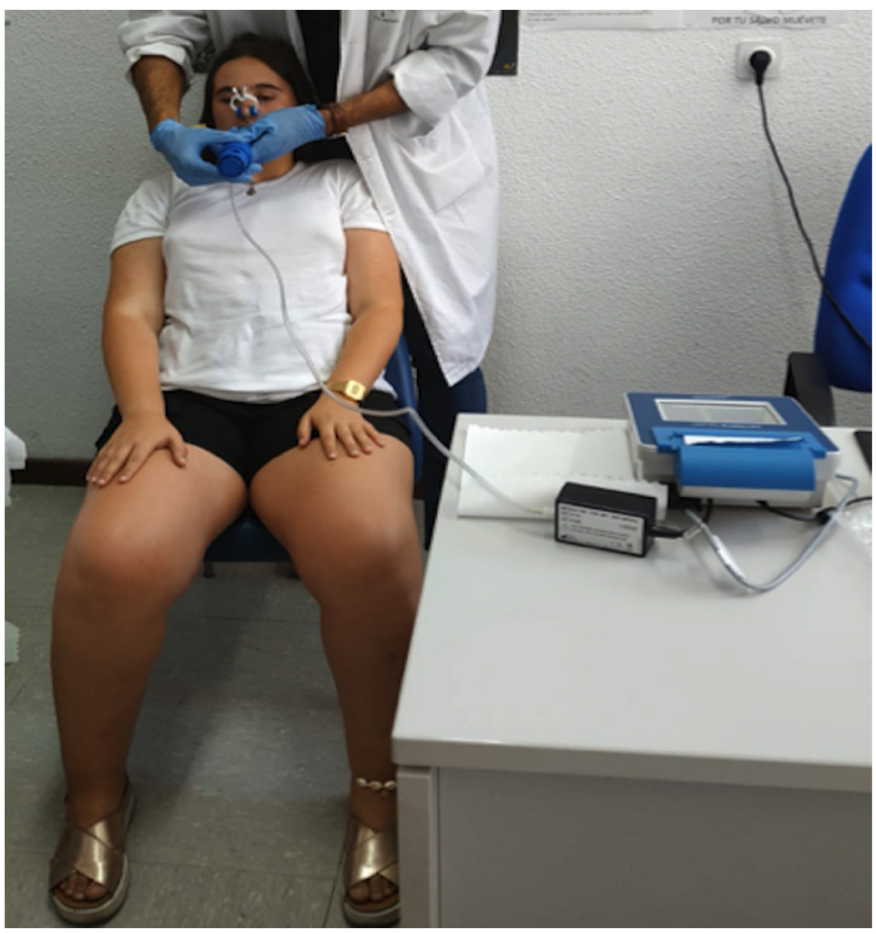

Figure 3. Trained physiotherapist and AIS patient using a peak inspiratory mouth pressure monitor.

\subsection{Data Analysis}

Data were described by means and standard deviation for continuous variables and by frequencies and percentages for categorical variables. The Kolmogorov-Smirnov test was used to evaluate the normality of the data, and the Levene test was used for homoscedasticity. To measure the relationships between continuous variables, the Pearson- $\mathrm{R}$ correlation coefficient was used as all of them presented normal distribution. Differences in the respiratory variables between the treatment groups were determined by means of an analysis of the covariance, where the treatment group was the factor, the respiratory parameters were the result variables, and the height and degrees of curve measured on the basis of that Cobb angle were the covariates. The coefficient of determination R2 was used as an effect size measure. According to Cohen [21], R2 can be classified as insignificant when it is less than 0.02 , small if it is between 0.02 and 0.15 , medium if it is between 0.15 and 0.35 , and 
large if it is greater than 0.35. Data analysis was conducted using the statistical package for social sciences version 21 (SPSS Inc., Chicago, IL, USA) and the statistical program MedCalc ${ }^{\circledR}$ Statistical Software version 19.6 (MedCalc Software Ltd., Ostend, Belgium, https://www.medcalc.org; 2020). The confidence level was set at $95 \%(p<0.05)$.

\section{Results}

The sociodemographic, clinical, and anthropometric characteristics of the participants are shown in Table 1. Fifteen participants were recruited and evaluated, eleven patients were female and four were male. Eight patients underwent conservative treatment (four exercises and four orthotic), and seven received no intervention.

Table 1. Sociodemographic characteristics.

\begin{tabular}{|c|c|c|c|c|c|c|c|c|}
\hline $\mathbf{N}$ & Sex & $\begin{array}{l}\text { Age } \\
\text { (Year) }\end{array}$ & $\begin{array}{l}\text { Height } \\
(\mathrm{cm})\end{array}$ & $\begin{array}{l}\text { Weight } \\
\text { (Kg) }\end{array}$ & $\begin{array}{c}\text { Body Mass Index } \\
\left(\mathrm{Kg} / \mathrm{m}^{2}\right)\end{array}$ & $\begin{array}{c}\text { Main Curve } \\
\text { Degrees }\end{array}$ & Type & Treatment \\
\hline 1 & $\mathrm{~F}$ & 12 & 1.48 & 42.0 & 19.17 & 17 & King IV & Brace \\
\hline 2 & M & 14 & 1.71 & 52.0 & 17.78 & 16 & King IV & No intervention \\
\hline 3 & M & 13 & 1.74 & 57.0 & 18.83 & 13 & King IV & No intervention \\
\hline 4 & $\mathrm{~F}$ & 14 & 1.51 & 81.0 & 35.52 & 12 & King IV & Brace \\
\hline 5 & $\mathrm{~F}$ & 14 & 1.65 & 62.0 & 22.77 & 16 & King I & GPR \\
\hline 6 & $\mathrm{~F}$ & 10 & 1.45 & 40.0 & 19.02 & 10 & King II & GPR \\
\hline 7 & $\mathrm{~F}$ & 14 & 1.67 & 44.0 & 15.78 & 27 & King I & Brace \\
\hline 8 & $\mathrm{~F}$ & 13 & 1.61 & 48.0 & 18.52 & 21 & King II & GPR \\
\hline 9 & $\mathrm{~F}$ & 12 & 1.44 & 42.0 & 20.25 & 18 & King I & No intervention \\
\hline 10 & $\mathrm{~F}$ & 13 & 1.54 & 44.0 & 18.55 & 10 & King II & No intervention \\
\hline 11 & M & 14 & 1.67 & 45.5 & 16.31 & 10 & King IV & No intervention \\
\hline 12 & M & 13 & 1.69 & 55.0 & 19.26 & 10 & King II & No intervention \\
\hline 13 & $\mathrm{~F}$ & 14 & 1.68 & 73.0 & 25.86 & 12 & King I & No intervention \\
\hline 14 & $\mathrm{~F}$ & 16 & 1.54 & 48.5 & 20.45 & 37 & King II & Brace \\
\hline 15 & $\mathrm{~F}$ & 16 & 1.65 & 64.0 & 23.50 & 16 & King II & GPR \\
\hline Total & $\begin{array}{c}\mathrm{F}=73.3 \% \\
\mathrm{M}=26.7 \%\end{array}$ & $\begin{array}{c}13 \pm 12 \\
(\mathrm{~m} \pm \mathrm{SD})\end{array}$ & $\begin{array}{c}1.60 \pm 0.10 \\
(\mathrm{~m} \pm \mathrm{SD})\end{array}$ & $\begin{array}{c}53.2 \pm 12.2 \\
(\mathrm{~m} \pm \mathrm{SD})\end{array}$ & $\begin{array}{c}20.77 \pm 4.86 \\
(\mathrm{~m} \pm \mathrm{SD})\end{array}$ & $\begin{array}{c}16 \pm 7 \\
(\mathrm{~m} \pm \mathrm{SD})\end{array}$ & $\begin{array}{c}\mathrm{I}=26.7 \% \\
\mathrm{III}=40.0 \% \\
\mathrm{IV}=33.3 \%\end{array}$ & $\begin{array}{c}\text { No intervention }=46.7 \% \\
\text { GPR }=26.7 \% \\
\text { Brace }=26.7 \%\end{array}$ \\
\hline
\end{tabular}

Abbreviations: F, female; M, male; m, median; SD, standard deviation; GPR, Global Posture Reeducation.

The correlation analysis (Table 2) showed a statistically significant relationship between height, measured in centimeters, with the reference MIP $\left(\mathrm{cmH}_{2} \mathrm{O}\right)$ and FVC (liters) $(r=0.650$ and $r=0.673 ; p<0.01)$. The weight variable, measured in $\mathrm{kg}$, also correlated significantly with the reference MIP $\left(\mathrm{cmH}_{2} \mathrm{O}\right)(r=0.727 ; p<0.01)$. The degrees of the curve, measured using the Cobb technique, significantly correlated with the variable FVC \% $(r=-0.648 ; p<0.01)$.

Table 2. Pearson-R correlation between respiratory parameters and morphological and sociodemographic variables.

\begin{tabular}{|c|c|c|c|c|c|c|c|c|c|c|}
\hline & \multicolumn{2}{|c|}{$\begin{array}{l}\text { Age } \\
\text { (Year) }\end{array}$} & \multicolumn{2}{|c|}{$\begin{array}{l}\text { Height } \\
\text { (cm) }\end{array}$} & \multicolumn{2}{|c|}{$\begin{array}{l}\text { Weight } \\
\text { (Kg) }\end{array}$} & \multicolumn{2}{|c|}{$\begin{array}{l}\text { Body Mass Index } \\
\qquad\left(\mathrm{Kg} / \mathrm{m}^{2}\right)\end{array}$} & \multicolumn{2}{|c|}{ Main Curve Degrees } \\
\hline & Coef & $p$ & Coef & $p$ & Coef & $p$ & Coef & $p$ & Coef & $p$ \\
\hline MIP & -0.131 & 0.643 & 0.113 & 0.689 & 0.229 & 0.412 & 0.318 & 0.248 & -0.266 & 0.338 \\
\hline MIP ref & 0.290 & 0.294 & 0.650 & $0.009 * *$ & 0.727 & $0.002 * *$ & 0.215 & 0.442 & -0.293 & 0.289 \\
\hline MIP (\% pred) & -0.112 & 0.691 & 0.029 & 0.919 & 0.141 & 0.615 & 0.286 & 0.302 & -0.098 & 0.729 \\
\hline FVC (L) & 0.224 & 0.422 & 0.673 & $0.006^{* *}$ & 0.485 & 0.067 & 0.007 & 0.980 & -0.400 & 0.140 \\
\hline FVC \% & -0.228 & 0.414 & 0.418 & 0.121 & -0.028 & 0.922 & -0.193 & 0.490 & -0.648 & $0.009 * *$ \\
\hline $\mathrm{FEV}_{1}(\mathrm{~L})$ & 0.207 & 0.459 & 0.426 & 0.113 & 0.465 & 0.081 & 0.229 & 0.413 & -0.185 & 0.510 \\
\hline $\mathrm{FEV}_{1} \%$ & -0.033 & 0.908 & 0.227 & 0.417 & 0.158 & 0.573 & 0.172 & 0.541 & -0.251 & 0.367 \\
\hline $\mathrm{FEV}_{1} / \mathrm{FVC}$ & 0.345 & 0.208 & -0.004 & 0.990 & 0.347 & 0.205 & 0.393 & 0.147 & 0.338 & 0.217 \\
\hline $\mathrm{FEV}_{1} / \mathrm{FVC} \%$ & 0.252 & 0.364 & 0.065 & 0.819 & 0.342 & 0.212 & 0.365 & 0.181 & 0.249 & 0.370 \\
\hline PEF (L/S) & 0.259 & 0.351 & 0.304 & 0.270 & 0.454 & 0.089 & 0.286 & 0.302 & -0.045 & 0.873 \\
\hline PEF \% & 0.207 & 0.460 & 0.135 & 0.633 & 0.412 & 0.127 & 0.404 & 0.135 & -0.053 & 0.850 \\
\hline
\end{tabular}

Abbreviations: MIP, maximum inspiratory pressure measured in $\mathrm{cmH}_{2} \mathrm{O}$; ref, reference; \%pred, percentage predicted; FVC, forced vital capacity; $\mathrm{FEV}_{1}$, forced expiratory volume $1 \mathrm{~s}$; PEF, peak expiratory flow; L/S, liters/second; Coef, coefficient; $p, p$-value. ${ }^{* *} p<0.01$. 
With respect to the different types of conservative management, the strength scores were highest for the GPR treatment, followed by no intervention, with the lowest scores being obtained for the orthotic brace (Figure 4). Statistically significant differences were observed, corrected for the height and magnitude of the curve, in the predictive MIP $\left(\% \mathrm{cmH}_{2} \mathrm{O}\right)(p<0.05)$. The results can be seen in Table 3 .

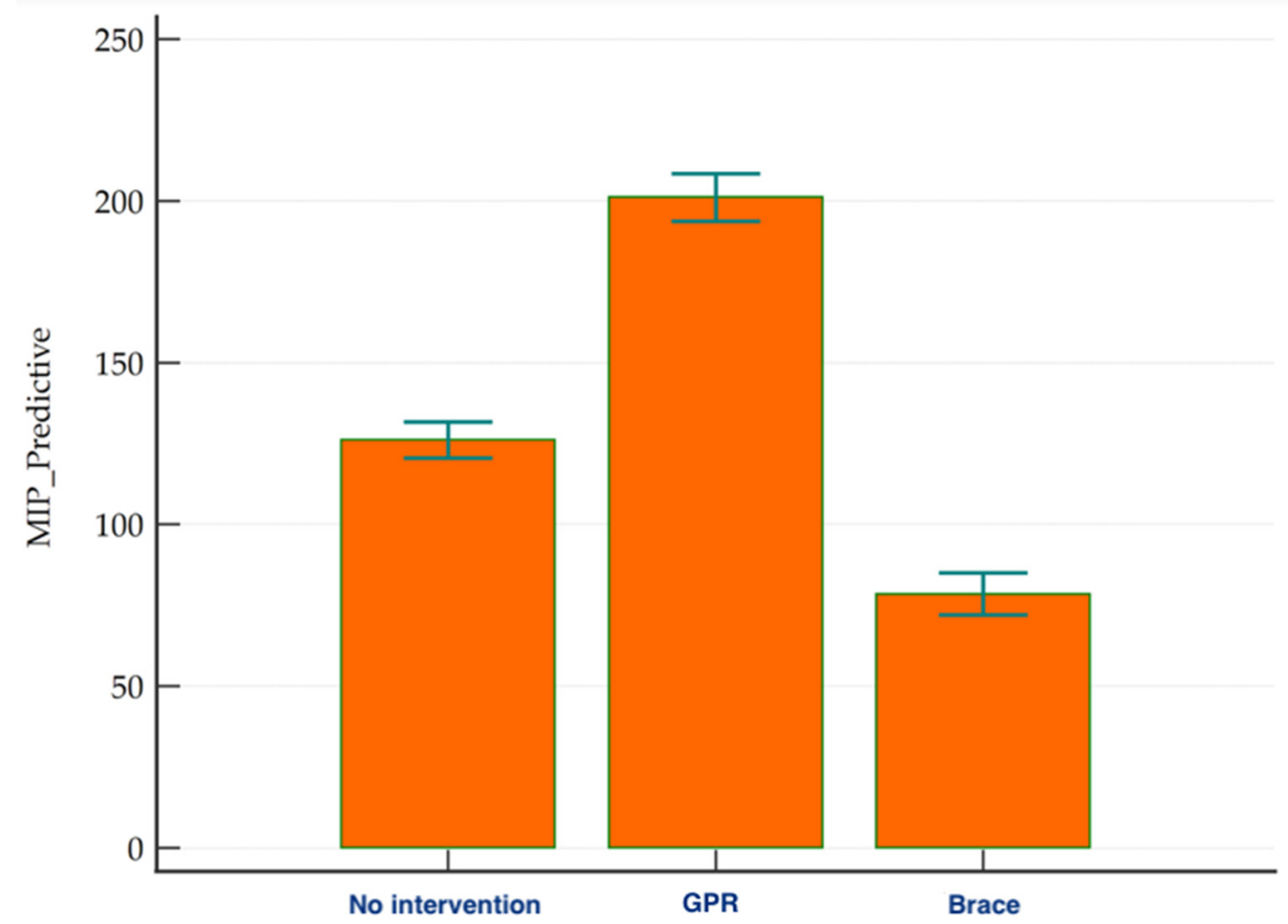

Figure 4. Strength scores for the different groups (GPR: Global Postural Reeducation; MIP: maximum inspiratory pressure measured in $\mathrm{cmH}_{2} \mathrm{O}$ ).

Table 3. Mean difference in treatment groups.

\begin{tabular}{|c|c|c|c|c|c|c|c|c|}
\hline & \multicolumn{2}{|c|}{$\begin{array}{l}\text { No Intervention } \\
\qquad(n=7)\end{array}$} & \multicolumn{2}{|c|}{$\begin{array}{c}\text { GPR } \\
(n=4)\end{array}$} & \multicolumn{2}{|c|}{$\begin{array}{l}\text { Brace } \\
(n=4)\end{array}$} & \multirow{2}{*}{$\begin{array}{l}\text { Ancova } \\
p \text {-Value }\end{array}$} & \multirow{2}{*}{$\begin{array}{c}\text { Effect Size } \\
\text { Eta-2 }\end{array}$} \\
\hline & Mean & SD & Mean & SD & Mean & SD & & \\
\hline MIP & 97.00 & 47.06 & 142.75 & 49.90 & 56.50 & 20.98 & 0.103 & 0.366 \\
\hline MIP ref & 77.43 & 9.62 & 70.00 & 6.68 & 73.50 & 9.61 & 0.108 & 0.359 \\
\hline MIP (\% pred) & 126.11 & 57.30 & 201.12 & 55.22 & 78.46 & 33.10 & $0.045 *$ & 0.463 \\
\hline FVC (L) & 3.57 & 0.78 & 2.17 & 1.22 & 2.77 & 0.37 & 0.146 & 0.319 \\
\hline FVC \% & 94.14 & 7.78 & 65.25 & 36.68 & 79.00 & 3.92 & 0.147 & 0.318 \\
\hline $\mathrm{FEV}_{1}(\mathrm{~L})$ & 2.82 & 0.85 & 1.94 & 1.21 & 1.98 & 0.87 & 0.510 & 0.126 \\
\hline $\mathrm{FEV}_{1} \%$ & 88.14 & 20.46 & 66.25 & 36.99 & 65.00 & 26.23 & 0.336 & 0.196 \\
\hline $\mathrm{FEV}_{1} / \mathrm{FVC}$ & 79.05 & 14.97 & 89.16 & 12.18 & 69.57 & 27.24 & 0.216 & 0.264 \\
\hline $\mathrm{FEV}_{1} / \mathrm{FVC} \%$ & 93.29 & 17.78 & 102.75 & 13.57 & 80.75 & 30.72 & 0.239 & 0.249 \\
\hline PEF L/S & 4.26 & 1.95 & 3.63 & 2.85 & 3.01 & 1.72 & 0.741 & 0.058 \\
\hline PEF \% & 66.43 & 29.06 & 61.00 & 42.43 & 50.00 & 31.18 & 0.589 & 0.101 \\
\hline
\end{tabular}

Abbreviations: MIP, maximum inspiratory pressure; Ref, reference; \%pred, percentage predicted; FVC, forced vital capacity; FEV $_{1}$, forced expiratory volume $1 \mathrm{~s}$; PEF, peak expiratory flow; L/S, liters/second; SD, standard deviation; GPR, Global Posture Reeducation. ${ }^{*} p<0.05$.

\section{Discussion}

In this study, it was observed that adolescents under GPR treatment presented greater inspiratory muscle strength when compared to those subjected to a brace or to no intervention. However, we did not find differences between the different cases with respect to lung function and the lack of measurements before the treatments must be considered. 
In general, analyzing the entire sample, our patients presented higher values for inspiratory muscle strength $\left(98.4 \mathrm{cmH}_{2} \mathrm{O}\right.$ and $133.4 \%$ predictive), when compared to previously published data for this population (data not presented in tables). Yagci et al. [22] studied 27 adolescents with AIS and found a predictive MIP of $48 \%$, which is well below normal. Saraiva et al. [23] observed values between 49 and $61 \mathrm{cmH}_{2} \mathrm{O}$. The differences observed between such studies may be due, on the one hand, to the measurement procedure, or on the other to the ethnic characteristics of the population. Regarding the procedure, the values achieved for MIP will be different if the measurement is made on the basis of the functional residual capacity or on the basis of the residual volume.

The analysis by type of treatment subgroup revealed that those patients who underwent GPR presented higher values than those in the no intervention group or the orthotic group. These differences were maintained even when the size of the curve and the height of the patients were adjusted. Although there is little scientific evidence regarding the benefits of the GPR method on respiratory variables, in clinical practice, the focus is on the respiratory system [24]. Studies performed in healthy subjects or in other patient populations have shown positive effects on respiratory muscle strength and thoracic mobility in healthy individuals [15,16]. Moreno et al. [15] demonstrated an improvement in inspiratory and expiratory muscle strength and thoracoabdominal mobility of sedentary young males. They observed increases of $40.0 \mathrm{cmH}_{2} \mathrm{O}$ in MIP and $50.0 \mathrm{cmH}_{2} \mathrm{O}$ in MEP in the experimental group after 16 sessions of GPR. In addition, they found an increase in thoracoabdominal expansibility in terms of the circumference values obtained at the axillary, xiphoid and abdominal level, measured using the cirtometry technique [15].

The GPR method states that respiratory alterations are the result of excessive shortening of the respiratory musculature [24]. Several factors are associated with this shortening, including stress, respiratory disease, muscle weakness, and inappropriate posture. All of the postural exercises involved in the GPR method permit respiratory muscle stretching. Muscle shortening results from modifications in the contraction proteins and metabolism of the mitochondria, with a reduction in the number of sarcomeres and an increase in the deposition of connective tissue so that the soft tissue loses elasticity [25]. Sarcomere shortening during activation is achieved by relative gliding of actin filaments over myosin filaments [25]. Stretching a muscle fiber causes a serial increase in the number of sarcomeres and a better interaction between actin and myosin filaments, by virtue of the increased functional length of the muscle. As a consequence, an increase in muscle strength associated with stretching and a loss of muscle strength associated with muscle shortening $[26,27]$.

With respect to lung function, we did not find significant differences between the groups. The GPR method improves chest expansibility [15], and a significant association between chest expansion and vital capacity has been demonstrated [20]. However, research about the effect of GPR on lung function is scarce, especially in spinal diseases. Studies in adolescents with scoliosis treated with GPR could not be located, nonetheless some interesting ones on ankylosing spondylitis were considered. Although Durmus et al. [17] and Coksevim et al. [28] achieved better results treating ankylosing spondylitis with GPR than using a conventional exercise program regarding to $\mathrm{FVC}, \mathrm{FEV}_{1}$ and $\mathrm{PEF}$ parameters, González-Medina et al. recently conducted a meta-analysis on GPR in ankylosing spondylitis showing that there is no evidence which suggests that GPR is better than other exercise considering respiratory parameters [29]. Though Lomas-Vega et al. determined that GPR is useful in spinal disorders [30], more research is needed to clarify its effects in respiratory function of these patients.

Some limitations of this study must be considered when interpreting the results. Firstly, we used a small sample, and the generalizability of the results to other children with AIS is limited. Secondly, the retrospective case series nature of our design does not allow causal relationships to be established. For this reason, future studies should explore prospective designs to assess the causal relationship with a larger and more diverse population. In this line, a randomized controlled trial following CONSORT guideline will 
be held in the future. In addition, we recommend the inclusion of functional measures related to respiratory variables, such as the degree of dyspnea or tolerance to effort in activities of daily living.

\section{Conclusions}

The results of this case series show a possible relation in which those patients who underwent treatment with the GPR method present greater inspiratory muscle strength (regardless of the size of the curve and height), when compared with the no intervention and brace cases. Lung function did not exhibit any differences between the different cases. Nevertheless, further studies are needed to confirm the generalizability of the results.

Author Contributions: Conceptualization, F.L.-M., R.L.-V., J.A.A.-O. and S.L.d.O.-S.; methodology, N.Z.-A., J.A.A.-O. and R.L.-V.; software, R.L.-V.; formal analysis, R.L.-V. and S.L.d.O.-S.; investigation, A.J.I.-V.; resources, F.L.-M., A.J.I.-V. and J.A.A.-O.; data curation, F.L.-M., S.L.d.O.-S., N.Z.-A. and A.J.I.-V.; writing —original draft preparation, F.L.-M. and S.L.d.O.-S.; writing-review and editing, F.L.-M. and R.L.-V.; supervision, S.L.d.O.-S.; project administration, N.Z.-A. and F.L.-M.; All authors have read and agreed to the published version of the manuscript.

Funding: This research received no external funding.

Institutional Review Board Statement: The study was conducted according to the guidelines of the Declaration of Helsinki, and approved by the Ethics Committee of Jaen Hospital Complex (Code 0594-N-19, date of approval 30 May 2019).

Informed Consent Statement: Informed consent was obtained from all subjects involved in the study.

Data Availability Statement: The data presented in this study are available on request from the corresponding author.

Acknowledgments: Authors want to thank Centro de Fisioterapia Biobalance for the pictures and clinical support.

Conflicts of Interest: The authors declare no conflict of interest.

\section{References}

1. Di Meglio, A.; Canavese, F. The immature spine: Growth and idiopathic scoliosis. Ann. Transl. Med. 2020, 8, 22. [CrossRef]

2. Grossman, D.C.; Curry, S.J.; Owens, D.K.; Barry, M.J.; Davidson, K.W.; Doubeni, C.A.; Epling, J.W.J.; Kemper, A.R.; Krist, A.H.; Kurth, A.E.; et al. Screening for Adolescent Idiopathic Scoliosis: US Preventive Services Task Force Recommendation Statement. JAMA 2018, 319, 165-172.

3. Jagger, F.; Tsirikos, A.I.; Blacklock, S.; Urquhart, D.S. Adaptation to reduced lung function in children and young people with spinal deformity. J. Clin. Orthop. Trauma 2020, 11, 191-195. [CrossRef] [PubMed]

4. Newton, P.O.; Faro, F.D.; Gollogly, S.; Betz, R.R.; Lenke, L.G.; Lowe, T.G. Results of Preoperative Pulmonary Function Testing of Adolescents with Idiopathic Scoliosis. J. Bone Jt. Surg. 2005, 87, 1937-1946. [CrossRef]

5. Weinstein, S.L.; Dolan, L.; Wright, J.G.; Dobbs, M.B. Effects of Bracing in Adolescents with Idiopathic Scoliosis. N. Engl. J. Med. 2013, 369, 1512-1521. [CrossRef]

6. Lao, L.; Weng, X.; Qiu, G.; Shen, J. The role of preoperative pulmonary function tests in the surgical treatment of extremely severe scoliosis. J. Orthop. Surg. Res. 2013, 8, 32. [CrossRef] [PubMed]

7. Barrios, C.; Pérez-Encinas, C.; Maruenda, J.I.; Laguía, M. Significant Ventilatory Functional Restriction in Adolescents with Mild or Moderate Scoliosis during Maximal Exercise Tolerance Test. Spine 2005, 30, 1610-1615. [CrossRef]

8. Kaelin, A.J. Adolescent idiopathic scoliosis: Indications for bracing and conservative treatments. Ann. Transl. Med. 2020, 8, 28. [CrossRef]

9. Redding, G.J.; Mayer, O.H. Structure-Respiration Function Relationships Before and After Surgical Treatment of Early-onset Scoliosis. Clin. Orthop. Relat. Res. 2011, 469, 1330-1334. [CrossRef]

10. Canavese, F. Idiopathic scoliosis. Ann. Transl. Med. 2020, 8, 21. [CrossRef]

11. Ran, B.; Fan, Y.; Yuan, F.; Guo, K.; Zhu, X. Pulmonary function changes and its influencing factors after preoperative brace treatment in patients with adolescent idiopathic scoliosis: A retrospective case-control study. Medicine 2016, 95, e5088. [CrossRef]

12. Day, J.M.; Fletcher, J.; Coghlan, M.; Ravine, T. Review of scoliosis-specific exercise methods used to correct adolescent idiopathic scoliosis. Arch. Physiother. 2019, 9, 8. [CrossRef]

13. Dupuis, S.; Fortin, C.; Caouette, C.; LeClair, I.; Aubin, C. Global postural re-education in pediatric idiopathic scoliosis: A biomechanical modeling and analysis of curve reduction during active and assisted self-correction. BMC Musculoskelet. Disord. 2018, 19, 200. [CrossRef] 
14. Kim, K.-D.; Hwangbo, P.-N. Effects of the Schroth exercise on the Cobb's angle and vital capacity of patients with idiopathic scoliosis that is an operative indication. J. Phys. Ther. Sci. 2016, 28, 923-926. [CrossRef]

15. Moreno, M.A.; Catai, A.M.; Teodori, R.M.; Borges, B.L.A.; De Cesar, M.C.; Da Silva, E. Efeito de um programa de alongamento muscular pelo método de Reeducação Postural Global sobre a força muscular respiratória e a mobilidade toracoabdominal de homens jovens sedentários. J. Bras. Pneumol. 2007, 33, 679-686. [CrossRef]

16. Teodori, R.M.; Moreno, M.A.; Fiore Junior, J.F.; Oliveira, A.C.S. Alongamento da musculatura inspiratoria por intermedio da reeducacao postural global (RPG). Braz. J. Phys. Ther. 2003, 7, 25-30.

17. Durmuş, D.; Alaylı, G.; Uzun, O.; Tander, B.; Cantürk, F.; Bek, Y.; Erkan, L. Effects of two exercise interventions on pulmonary functions in the patients with ankylosing spondylitis. Jt. Bone Spine 2009, 76, 150-155. [CrossRef]

18. Weniger, C.D.; Fujak, A.; Hofner, B.; Fuchs, M.; Forst, R.; Richter, R.H. Long-term Results of Conservative Therapy of Adolescent Idiopathic Scoliosis Using the Cheneau Brace. Klin. Padiatr. 2019, 231, 248-254. [CrossRef]

19. King, H.A.; Moe, J.H.; Bradford, D.S.; Winter, R.B. The selection of fusion levels in thoracic idiopathic scoliosis. J. Bone Jt. Surg. Am. 1983, 65, 1302-1313. [CrossRef]

20. Nici, L.; Donner, C.; Wouters, E.; ZuWallack, R.; Ambrosino, N.; Bourbeau, J.; Carone, M.; Celli, B.; Engelen, M.; Fahy, B.; et al. American Thoracic Society/European Respiratory Society Statement on Pulmonary Rehabilitation. Am. J. Respir. Crit. Care Med. 2006, 173, 1390-1413. [CrossRef] [PubMed]

21. Cohen, J. A power primer. Psychol. Bull. 1992, 112, 155-159. [CrossRef]

22. Yagci, G.; Demirkiran, G.; Yakut, Y. In-brace alterations of pulmonary functions in adolescents wearing a brace for idiopathic scoliosis. Prosthetics Orthot. Int. 2019, 43, 434-439. [CrossRef] [PubMed]

23. Saraiva, B.M.; Araujo, G.S.; Sperandio, E.F.; Gotfryd, A.O.; Dourado, V.Z.; Vidotto, M. Impact of Scoliosis Severity on Functional Capacity in Patients with Adolescent Idiopathic Scoliosis. Pediatr. Exerc. Sci. 2018, 30, 243-250. [CrossRef]

24. Souchard, P. Reeducación Postural Global, 1st ed.; Elsevier: Barcelona, Spain, 2012.

25. Lieber, R.L.; Fridén, J. Muscle contracture and passive mechanics in cerebral palsy. J. Appl. Physiol. 2019, 126, 1492-1501. [CrossRef]

26. Rassier, D.E. Sarcomere mechanics in striated muscles: From molecules to sarcomeres to cells. Am. J. Physiol. Physiol. 2017, 313, C134-C145. [CrossRef] [PubMed]

27. Chen, J.; Hahn, D.; Power, G.A. Shortening-induced residual force depression in humans. J. Appl. Physiol. 2019, 126, 1066-1073. [CrossRef]

28. Coksevim, N.H.; Durmus, D.; Kuru, O. Effects of global postural reeducation exercise and anti-TNF treatments on disease activity, function, fatigue, mobility, sleep quality and depression in patients with active Ankylosing spondylitis: A prospective follow-up study. J. Back Musculoskelet. Rehabil. 2018, 31, 1005-1012. [CrossRef] [PubMed]

29. Gonzalez-Medina, G.; Perez-Cabezas, V.; Marin-Paz, A.-J.; Galán-Mercant, A.; Ruiz-Molinero, C.; Jimenez-Rejano, J.J. Effectiveness of Global Postural Reeducation in Ankylosing Spondylitis: A Systematic Review and Meta-Analysis. J. Clin. Med. 2020, 9, 2696. [CrossRef]

30. Lomas-Vega, R.; Garrido-Jaut, M.V.; Rus, A.; Del-Pino-Casado, R. Effectiveness of Global Postural Re-education for Treatment of Spinal Disorders: A Meta-analysis. Am. J. Phys. Med. Rehabil. 2017, 96, 124-130. [CrossRef] 